\title{
O TRABALHO DE HOMENS E MULHERES NO TURISMO RURAL EM SÃO JOSÉ DOS AUSENTES: O “LEVE" E O "PESADO"
}

THE WORK OF MEN AND WOMEN IN RURAL TOURISM IN SÃO JOSÉ DOS AUSENTES: "LIGHT" AND "HEAVY" WORK

EL TRABAJO DE HOMBRES Y MUJERES EN EL TURISMO RURAL EN SÃO JOSÉ DOS AUSENTES: LO "LIVIANO" Y LO "PESADO"

Raquel Lunardi

Professora do Instituto Federal de Educação, Ciência e Tecnologia Farroupilha - Raquel_lunardi@yahoo.com.br - Doutora em Desenvolvimento Rural, Mestre em Extensão Rural, Bacharel em Turismo.

\section{Marcelino de Souza}

Professor Associado da Faculdade de Ciências Econômicas e dos Programas de Pós-Graduação em Desenvolvimento Rural e Agronegócio da Universidade Federal do Rio Grande do Sul, Porto Alegre, Rio Grande do Sul. E-mail: marcelino.souza@uol.com.br. Doutor em Engenharia Agrícola, Mestre em Extensão Rural, Graduado em Engenharia Agronômica.

\section{Fátima Perurena}

Professora Adjunta do Departamento de Ciências Sociais da Universidade Federal de Santa Maria, Santa Maria, Rio Grande do Sul. E-Mail: perurena@ gmail.com. Doutora em Ciências Sociais, Mestre em Ciência Política, Bacharel/

Licenciada em Ciências Sociais.

Data de Submissão: 01/09/2014

Data de Aprovação: 13/11/2014 
Resumo: Este trabalho tem como objetivo estudar as relações de trabalho na atividade turística no meio rural de São José dos Ausentes. As mudanças produtivas ocorridas no meio rural por meio da diversificação das culturas agrícolas e da inserção de atividades não agrícolas no espaço rural têm permitido um novo debate sobre o desenvolvimento rural. Novas formas de uso do espaço rural estão postas e com elas novas formas de organização da vida familiar, cuja divisão do trabalho é uma das esferas mais afetadas. A proximidade entre as tarefas realizadas no ambiente doméstico com a atividade produtiva turismo rural permite que homens e mulheres desenvolvam e reestruturem suas funções dentro da unidade familiar. Porém, não se sabe se estas mudanças permitem transformações na divisão sexual do trabalho e se isto possibilita repensar as estruturas de gênero no meio rural. Para compreender essa teia de relações, foi preciso refletir sobre as relações internas à família, como a organização das tarefas diárias, o sistema produtivo e a participação de cada membro nas decisões que envolvem o grupo familiar. Para isso pesquisaramse sete famílias pluriativas e seis famílias agrícolas no meio rural do município de São José dos Ausentes, RS. De forma geral, pode-se sinalizar para uma reprodução da forma tradicional da divisão sexual do trabalho nas famílias rurais pesquisadas, sobretudo no que diz respeito ao trabalho feminino no momento em que velhas práticas são reafirmadas pelo turismo.

Palavras-Chave: Turismo rural. Trabalho. Gênero.

Abstract: This work studies work relations in tourism activity in the rural environment of São José dos Ausentes. The production changes that have occurred in the rural environment, through the diversification of agricultural crops and the insertion of non-agricultural activities in the rural space, have led to a new debate on rural development. New forms of use of the rural space are proposed, and with them, new forms of organization of 
Family life, with the division of labor being one of the spheres most affected. The close association between tasks carried out in the domestic environment and the production activity of rural tourism enables men and women to develop and restructure their functions within the family unit. However, it is not known whether these changes lead to transformations in the division of labor between the sexes, and whether enable a rethinking of gender structures in the rural environment. To understand this web of relationships, it was necessary to reflect on the relationships within the family, such as the organization of daily tasks, the production system, and the participation of each member in decisions involving the family group. For this, seven pluriactive families and six agricultural families were researched, in the rural environment of the municipality of São José dos Ausentes, RS. In general, it was found that the traditional division of labor between the sexes is reproduced in the families researched, particularly when it comes to women's work, at the time when the old practices are reaffirmed by tourism.

Keywords: Rural tourism. Work. Gender.

Resumen: Este trabajo tiene como objetivo estudiar las relaciones de trabajo en la actividad turística en el medio rural de São José dos Ausentes. Los cambios productivos ocurridos en el medio rural por medio de la diversificación de las culturas agrícolas y de la incorporación de actividades no agrícolas en el espacio rural han posibilitado un nuevo debate sobre el desarrollo rural. Se plantean nuevas formas de uso del espacio rural y con ellas nuevas formas de organización de la vida familiar, donde la división del trabajo es una de las esferas más afectadas. La proximidad entre las tareas realizadas en el ambiente doméstico con la actividad productiva del turismo rural permite que hombres y mujeres desarrollen y reestructuren sus funciones dentro de la unidad familiar. Sin embargo, no se sabe si estos cambios permiten transformaciones en la división por sexo 
del trabajo y si esto posibilita repensar las estructuras de género en el medio rural. Para comprender ese enmarañado de relaciones fue preciso reflexionar sobre las relaciones internas de la familia, como la organización de las tareas diarias, el sistema productivo y la participación de cada miembro en las decisiones que involucran al grupo familiar. Para ello se estudiaron siete familias pluriactivas y seis familias agrícolas en el medio rural del municipio de São José dos Ausentes, RS. De modo general, se pudo observar una reproducción de la forma tradicional de la división por sexo del trabajo en las familias rurales investigadas, sobre todo en lo que respecta al trabajo femenino en un momento en el que las viejas prácticas son reafirmadas por el turismo.

Palabras Clave: Turismo rural. Trabajo. Género.

INTRODUÇÃO

s mudanças ocorridas no meio rural brasileiro, especialmente depois
da década de 70 , trazem com elas o desenvolvimento de novas
estratégias de reprodução família, como a inserção de atividades não agrícolas. Assim, surgem novas formas de uso do espaço rural relacionadas ao consumo de novos produtos e serviços, o que têm permitido que o produtor rural, que era somente supridor de matéria-prima, passe a ser um prestador de serviços por meio de opções de lazer diversificando suas formas produtivas. Esta última afirmação tem incentivado muitos agricultores a desenvolverem o turismo, alterando o ritmo de vida local e familiar, a estrutura na divisão das atividades, tanto no turismo quanto na agricultura e no ambiente doméstico, assim como os valores sociais e culturais dos agentes envolvidos.

Esta nova configuração do meio rural traz consigo mudanças significativas na organização do trabalho familiar e é nesse sentido que se pretende, com este estudo, averiguar como é dada a organização do trabalho em empreendimentos de turismo rural. Para isso, buscou-se descrever as práticas laborais masculinas 
ISSN: 1983-7151

e femininas realizadas nos ambientes produtivo e reprodutivo onde acontece o turismo rural. Para esse entendimento, utilizaram-se os estudos das autoras Hirata e Kergoat (2007), Morell e Bock (2008) e Rivera (2000). O primeiro forneceu suporte em torno da compreensão da separação e da hierarquização do trabalho. O segundo traz um conjunto de estudos que evidencia o trabalho da mulher, em que foi possível identificar distanciamentos e aproximações. Estes estudos estão fundamentadas pelos regimes de gênero e destacam que a divisão do trabalho ainda está centrada no sistema patriarcal. A terceira referência mencionada trouxe o entendimento dos fatores internos e externos que estruturam o trabalho da mulher no turismo rural, onde se evidenciaram aproximações com os dados empíricos apresentados neste artigo. Para Morell e Brandth (2007), as relações de gênero no meio rural são formadas nas tensões entre a evolução de forças dos contratos sociais e as forças de trabalho, sendo estes os principais elementos na organização social e econômica das famílias, sobretudo de mulheres. Dessa forma, trazem-se, durante o decorrer de todo o texto, os resultados da pesquisa e sua interface com os referenciais supracitados.

Para se identificar esta nuança, buscou-se subsídio empírico em sete propriedades de turismo rural no município de São José dos Ausentes, região dos Campos de Cima da Serra. A região foi escolhida pela sua importância no segmento turístico do meio rural gaúcho, sendo considerada um dos principais destinos de turismo rural. A unidade de análise desta pesquisa foram famílias rurais $^{1}$ pluriativas. Optou-se pela família como unidade de análise, pois se entende que é a partir dela que se organizam as atividades produtivas, sociais, morais e de trabalho dos diferentes membros integrantes, e é a partir dela que se estabelecem as estratégias individuais e coletivas que visam garantir a reprodução social do grupo (SCHNEIDER, 2001). Partindo de uma abordagem qualitativa, optou-se pela observação não participante e pela entrevista semidirigida como instrumentos de pesquisa. Foram realizadas vinte e uma entrevistas, sendo que uma foi direcionada ao homem, outra à mulher e outra

1 Para Schneider (2001, p. 170) a "[...] família rural é entendida como um grupo social que compartilha um mesmo espaço (não necessariamente uma mesma habitação) e possui em comum a propriedade de um pedaço de terra. Esse coletivo está ligado por laços de parentesco e consanguinidade (filiação) entre si, podendo a ele pertencer, eventualmente, outros membros não consanguíneos (adoção)". 
à caracterização da propriedade, sendo esta última possível ser respondida por qualquer membro da família. Os resultados da pesquisa são trazidos nos itens 2, 3 e 4, sendo estes discutidos à luz das bibliografias referendadas anteriormente. Buscou-se essa interlocução entre dados e referencial teórico por se entender que ambos não devem ser indissociáveis e assim contribuir para melhor entendimento do leitor.

Dessa forma, o texto está estruturado em uma pequena introdução. No item 2, relata-se o turismo rural em São José dos Ausentes, bem como o seu histórico, as motivações e o contexto atual da atividade. No item 3, mostramse as formas de trabalho realizados por homens e mulheres nas propriedades de turismo rural. No item 4, que referenciam-se os significados do trabalho no turismo rural e por último a conclusão.

\section{TURISMO RURAL EM SÃO JOSÉ DOS AUSENTES}

A atividade turística no meio rural da Região dos Campos de Cima da Serra teve suas primeiras iniciativas na década de 1990. Vendo a situação financeira se agravar a cada ano, resultado da crise na pecuária, que era a principal fonte de receita da região naquele momento, os agricultores decidiram reagir a esta situação de empobrecimento do meio rural, buscando novas estratégias de reprodução econômica e social fora da atividade agrícola. É neste momento que as famílias decidem investir em atividades não agrícolas como o turismo rural.

Num primeiro momento, o turismo rural era uma atividade produtiva complementar da receita para as famílias, logo, em muitas propriedades, tornou-se a principal fonte geradora de receita e também de mudanças sociais e culturais. As primeiras iniciativas de turismo rural foram realizadas entre os anos de 1992 e 1996, sendo que no ano de 2000 predominou a abertura de novos empreendimentos turísticos. Tendo em vista esta nova atividade de desenvolvimento para o meio rural local, agricultores, instituições, organizações e associações municipais e estaduais lançaram mão de um repertório de estratégias no intuito de promover a atividade turística. Essas iniciativas culminaram na estruturação da rota turística "Campos de Cima da Serra". Concomitante a esta, outras ações foram realizadas pelos poderes 
públicos municipais que se constituíram em ações vitais para a visualização estadual e nacional da região, como a divulgação em rede nacional por meio dos programas da Rede Globo de televisão, como a novela "O Profeta". Após estes acontecimentos, foi elaborada, pelo Secretário Municipal de Turismo da época, uma cavalgada que passava por algumas das propriedades, sendo que estas começaram a oferecer alguns tipos de serviços para os cavalarianos, como almoço e pouso nos galpões. Foi neste momento que surgiu a possibilidade da exploração qualificada do turismo nesta região. A cavalgada ainda existe, percorrendo o mesmo trajeto, porém mais bem estruturada.

Além das prefeituras municipais e do Governo do Estado, que forneceram especialmente o aporte financeiro às iniciativas, outras instituições participaram ativamente na organização, consolidação e conformação do turismo rural na Região dos Campos de Cima da Serra, como o Serviço de Apoio às Micro e Pequenas Empresas no Rio Grande do Sul (SEBRAE-RS) e a Associação Riograndense de Empreendimentos de Assistência Técnica e Extensão Rural (EMATER/ASCAR-RS).

A atuação do SEBRAE deu-se na elaboração e na consolidação do projeto de implantação do turismo na região, prestando assessoria técnica aos empreendedores, bem como proporcionando cursos específicos da área de turismo e divulgando a rota para o restante do país. Já a atuação da EMATER deuse em nível local, sobretudo na adequação e na organização das propriedades para a recepção de turistas. Nesse sentido, os técnicos da EMATER buscaram atualizações por meio de cursos na área do turismo rural e de paisagismo para melhor colaborar com os novos empreendedores. Além disso, a EMATER é importante agente no acesso ao crédito rural (PRONAF), do qual uma das linhas é o Pronaf agroindústria, que contempla ações de investimentos em turismo rural. Esta instituição tem também papel importante como fomentadora/ promotora de eventos festivos e culturais no meio rural. A EMATER, apesar de ter um quadro de técnicos insuficiente para atender toda a região, atua junto ao agricultor na assessoria técnica agrícola e não agrícola necessária a estes empreendimentos. Outra instituição que colaborou, porém em menor grau, foi o Serviço Nacional de Aprendizagem Rural (SENAR), oferecendo cursos na área de alimentos. A Prefeitura Municipal de São José dos Ausentes foi fundamental 
para o desenvolvimento do turismo rural, dando apoio aos empreendedores por meio de orientações, cursos e marketing, atuando conjuntamente com o SEBRAE. A SETUR é citada pela maioria dos empreendedores como sendo fundamental, pois até hoje ela orienta o caminho para o desenvolvimento do turismo no município.

Não se pode deixar de mencionar os principais atores envolvidos neste processo: os agricultores. Nesta análise, pode-se dividi-los em duas categorias: os empreendedores e os empregados. Os empreendedores foram os principais agentes neste processo de desenvolvimento rural baseado em atividades não agrícolas. E os empregados e ou/terceirizados, um dos públicos que está sendo beneficiado, mesmo que o emprego seja temporário. Referente a este público, as mulheres tiveram um significativo envolvimento para o desenvolvimento do turismo neste local, participando das discussões sobre o turismo e, em alguns casos, sendo elas as principais incentivadoras na abertura das pousadas. Para Brandth e Haugen (2010b), o maior envolvimento feminino em novos negócios como o turismo rural deve-se ao fato da luta de mulheres por um novo status profissional e econômico dentro da propriedade. As mulheres foram as protagonistas, nesse local, para o desenvolvimento do negócio, em alguns casos, sem dúvida, as principais incentivadoras. Em outras propriedades, a decisão de investir foi do casal, que, depois de "combinar", chegou ao consenso de abrir as porteiras para receber o turista, tendo como base o apoio da Secretaria de Turismo do município. Brandth e Haugen (2010b) encontraram em suas pesquisas dados semelhantes. Para estes autores, a criação da nova empresa foi uma decisão da família. Porém, é preciso salientar a importância do acordo e apoio mútuo entre os casais, a combinação, os parceiros de negócios em que cada um contribui com suas competências e conhecimentos (BRANDTH; HAUGEN, 2010b).

Sendo iniciativa das mulheres ou dos homens, os relatos dos entrevistados evidencia que, para todas as propriedades, dois fatores foram decisivos para o investimento no turismo: o apoio do poder público, no caso, a Prefeitura Municipal; e a receita insuficiente obtida nas propriedades. Os investimentos do poder público partem de ações conjuntas entre poder local e instituições de Ensino ${ }^{2}$. Esse envolvimento foi fundamental para a descoberta das 2 A UFRGS, por meio do Núcleo de Fotografia da Faculdade de Biblioteconomia e Comunicação (FABICO), desenvolveu na década de 1990 o projeto "Povo e paisagem de São José dos 
potencialidades que o município oferecia, sobretudo os atrativos naturais, e também fez com que os proprietários valorizassem seu ambiente pela paisagem natural. Para Rivera (2000), os efeitos econômicos são os principais motivadores da atividade turística. Contudo, o turismo leva implícito outros fatores próprios de sua natureza, como os sociais e culturais, que outras atividades econômicas tradicionais, como a agricultura, não levam.

Muitas dificuldades foram enfrentadas no início, mesmo tendo o apoio do poder público local. As dificuldades variaram de propriedade para propriedade, e de homem para mulher. Os homens consideraram como principais dificuldades a questão da infraestrutura, sobretudo as relacionadas ao fornecimento de energia elétrica, às estradas e à comunicação. Já as mulheres consideraram como principal dificuldade o relacionamento com o turista, o contato com ele no atender e servir, características fundamentais da hospitalidade e que são de responsabilidade, sobretudo, das mulheres.

Apesar das dificuldades, que hoje são outras, diferentes das de quando iniciaram com o turismo, as pretensões são de manter o turismo rural e passar esta nova atividade produtiva para os filhos, permitindo que eles permaneçam no meio rural e preservem a propriedade. A tendência, e isso é justificado pela própria fala da comunidade e dos proprietários, é de que o turismo cresça ainda mais e se formate dentro de um novo modelo de desenvolvimento, "acompanhando a modernidade"3. No entanto, isso gera uma expectativa nos empreendedores, já que o principal produto das pousadas são os modos de vida e a cultura local, e a modernidade poderia estar transformando essas realidades sociais. A chegada do asfalto, o desenvolvimento de novas rotas, a ampliação de linhas de ônibus cortando praticamente todo o Estado, a construção de usinas hidrelétricas ${ }^{4}$ e o interesse de grandes agências e operadoras de turismo

Ausentes" e vem executando sistemática documentação fotográfica do Município, incluindo tanto os redutos naturais quanto as atividades da população de São José dos Ausentes, com o objetivo de sistematizar, por meio da coleta de imagens do ambiente natural e de seus elementos, visando assim contribuir com o desenvolvimento do turismo na região (www.ufrgs. br/fotografia).

3 Acompanhar a modernidade foi uma expressão usada pelos entrevistados que se refere ao acesso e à utilização de bens e serviços urbanos. Refere-se sobretudo às iniciativas tecnológicas, como a internet, a telefonia e os utensílios domésticos como o forno elétrico, a máquina de lavar louça, entre outros.

4 O governo federal tem uma proposta de construção de hidrelétricas na região. Uma destas hidrelétricas seria feita no rio que corta duas das pousadas pesquisadas, implicando a reor- 
pela região estariam atraindo novos investidores, como se observou em uma das propriedades em que um casal, de um município do Vale do Taquari, estava investindo na compra de terras próximas à cidade e com o projeto de empreendimento na área de hospedagem e na área de alimentação. Além disso, há uma preocupação constante com a preservação da natureza e da cultura local, com o ambiente natural "intocado" e a cultura expressa nas tarefas, na forma de preparar os alimentos, "di fazer as coisas... o mais natural possível!" (Janete). No entanto, foram unânimes nos depoimentos as perspectivas de se viver no meio rural, apesar das dificuldades e das limitações existentes, e da necessidade de enfrentar barreiras para não desistir.

\section{O TRABALHO DE HOMENS E MULHERES NO TURISMO RURAL EM SÃO JOSÉ DOS AUSENTES}

Oturismo nasfamíliaspesquisadasemergea partirdasdificuldadeseconômicas encontradas por essas famílias, e seu principal resultado é a reorganização do trabalho familiar. Porém essa reorganização ainda está baseada dentro da estrutura de divisão sexual do trabalho que segue a tradicional e tem como base o patriarcado. Esta estrutura segue os princípios de separação e hierarquização discutidas por Hirata e Kergoat (2007). O primeiro aspecto está relacionado ao sistema sexo/gênero, às atividades que são de homens e mulheres, e o segundo diz respeito ao valor destas atividades. Uma das inquietações deste estudo é entender como se constroem essas relações e que mudanças estão ocorrendo neste ambiente após o turismo. Tal discussão se faz importante no momento em que "novas atividades" são inseridas e que "antigas" são excluídas e/ou modificadas. Ocupações tradicionais, que passaram de geração para geração e que tinham importância econômica para a família, como a produção do queijo, são algumas vezes substituídas por outras, mais rentáveis, e que desprendem menos esforço físico. Porém, há que se destacar que a atividade "principal" das propriedades, a pecuária, não foi substituída pelo turismo, pelo contrário, ela foi reforçada no momento em que recursos e conhecimentos ${ }^{5}$ adquiridos no ganização da atividade, visto que deixariam de existir dois dos principais atrativos turísticos da região, o Cachoeirão dos Rodrigues e o Desvio dos Rios. O projeto ainda está em estudo.

5 Estes conhecimentos se referem ao contato com pessoas de diferentes áreas, sejam elas hóspedes ou que trabalham em instituições envolvidas com o turismo ou com a Prefeitura Municipal. 
desenvolvimento da atividade turística são aplicados na pecuária. É unânime nas famílias pesquisadas a importância que tem a atividade pecuária para o turismo e vice-versa, gerando assim uma complementação de receita e não uma dependência entre uma atividade e outra. Nenhuma das famílias sobrevive com recursos apenas de uma das atividades. E isso é salutar para os agricultores, pois eles mesmos procuraram no turismo rural uma complementação da receita e não uma atividade produtiva única e exclusiva. Assim, a pecuária não foi substituída, ela passou por reestruturação com a implementação do turismo, fato devido, principalmente, à mão de obra familiar.

O turismo é uma atividade que exige dos proprietários dedicação diária, especialmente nos períodos de alta temporada. A região é considerada como turística o ano todo. No entanto, há períodos, como as férias e os feriados prolongados, em que há maior fluxo de turistas. São nesses períodos em que há maiores oportunidades de trabalho temporário ou ocasionais. O trabalho no turismo rural provém basicamente do grupo doméstico, entendido como um sistema econômico e social baseado no convívio comum, na mesma residência. Além desse grupo, ainda se pode citar o grupo familiar, que compreende demais membros da família com algum tipo de parentesco (cunhada, prima, sobrinha), mas que não residem na pousada, e o grupo dos vizinhos, amigos, compadres, que são aqueles que moram nas proximidades da pousada, podendo ou não ter vínculo familiar.

A divisão do trabalho apresenta-se disposta a partir do sistema sexo/gênero, em que a pecuária "é coisa do homem" e o turismo "é coisa de mulher". "Coisa de homem e coisa de mulher" são conceitos relacionados e justificados por eles pela força física despendida para sua realização e o local onde este é realizado. O campo é o espaço do homem, logo, ele é o responsável pela pecuária. A casa é o espaço da mulher, logo, ela é a responsável pelo turismo e por tudo aquilo que esteja relacionado a esta atividade.

Atrelada ao campo, a terra dá o sustento da casa e a identidade profissional de agricultor (homem). Essa identidade foi construída historicamente e é por meio dela que tanto homens quanto mulheres identificam-se como membros de uma sociedade e como profissionais. Às mulheres, essa identidade é repassada por ser 'mulher de agricultor' e por fazer parte da cultura 'camponesa', como 
apresenta Carneiro (1998). Com o turismo rural, essa identidade passa por ressignificações, contudo, ela não é substituída por uma nova, mesmo que agora ela se reconheça como empresária do turismo rural. Como empresária, ela reforça sua identidade de agricultora, talvez pelo fato de o turismo exigir isso, que acaba por se constituir parte do produto turístico. Se antes do turismo elas eram donas de casa e agricultoras, hoje elas são donas de casa, agricultoras/pecuaristas e empresárias do turismo rural. Porém, cabe destacar que esta mudança de caracterização do perfil profissional pouco muda na sua posição/participação dentro da família. Ela continua sendo dona de casa e desempenhando trabalhos domésticos, e o homem continua sendo provedor da propriedade em todas as suas instâncias produtivas. Essas permanências podem estar relacionadas à propriedade da terra, propriedade legalizada de direito ou instituída socialmente. O homem continua sendo a referência, o responsável pela propriedade e, consequentemente, pela atividade que envolve o cultivo da terra. O que muda é o sentido do trabalho feminino, que agora passa a ser valorizado por elas e pelos homens.

Contudo, se, por um lado, o turismo rural permitiu maior visibilidade ao trabalho doméstico da mulher, por outro, ele reforçou a invisibilidade do trabalho feminino na pecuária. A isso está relacionado o fato desta atividade ser definida como predominantemente masculina, estar relacionada ao uso da terra, ou seja, ao campo, e também ao aumento das horas trabalhadas pelas mulheres dentro da casa. Anteriormente à existência da atividade turística, as mulheres "ajudavam" os homens na pecuária. Atualmente, com o turismo, isso é praticamente impossível, pois elas não têm tempo disponível para isso. As tarefas relacionadas ao turismo ocupam aproximadamente quinze horas diárias de trabalho, inviabilizando a ida da mulher para o campo. A ela são destinados trabalhos mais próximos, como o trato dos animais (alimentação) e os cuidados da horta.

A ajuda que a mulher dedica ao homem na pecuária é retribuída por ele no turismo, estimulando assim a cooperação entre os membros da família. Na maioria das pousadas, o trabalho do homem é considerado, tanto por elas como por eles, como "ajuda", sobretudo quando diz respeito às atividades realizadas dentro da casa. No entanto, há trabalhos que são específicos dos homens, como os passeios, as cavalgadas e a limpeza do pátio. As mulheres são 
as responsáveis pela maior parte das tarefas realizadas dentro da casa, como a alimentação e a limpeza, fundamentais na execução do turismo. Isso aponta para a proximidade existente entre as tarefas desempenhadas no turismo rural com as tarefas domésticas, identificada também em outros estudos, como os de Nogueira (2004), Garcia Ramón, Canoves e Valdovinos (1995), Rivera (2000) e Brandht e Haugen (2010a; 2010b), que demonstraram em seus trabalhos que as mulheres são as que realizam a maior parte do trabalho no turismo e o maior número de trabalhos combinados, com maior jornada de trabalho diário.

Segundo Rivera (2000, p. 161), as mulheres realizam cinco tipos de trabalhos diferentes dentro da propriedade: "[...] o trabalho doméstico, o trabalho no turismo, o trabalho agrícola, o trabalho para o autoconsumo e outra atividade remunerada". Perez e Valiente (2000) também destacam esta aproximação. Eles consideram o turismo rural como uma ampliação do trabalho doméstico das mulheres, pois este é realizado simultaneamente ao trabalho doméstico, tendo as mesmas características, podendo elas continuarem com sua atividade principal, que é a reprodução, ou seja, a realização do trabalho doméstico para a manutenção da família. Para Brandth e Haugen (2010a), essa continuação do trabalho doméstico para o turismo pode resultar na permanência das tradicionais práticas de gênero no rural. Atrelado a isso, as mulheres podem realizar esta atividade dentro do ambiente doméstico, podendo conciliar o atendimento aos turistas a seus familiares. Além disso, elas destacam a qualificação necessária para desenvolver tais atividades, a mesma que elas necessitam para realizar as tarefas domésticas, ou seja, o conhecimento popular adquirido com o passar do tempo e passado de geração a geração.

No turismo rural, as mulheres são as responsáveis pela alimentação e tudo o que a envolve, como, por exemplo, os cuidados com a horta (plantio e colheita dos alimentos), trato dos pequenos animais (vacas e aves), relacionamento com os fornecedores de matéria-prima para elaboração de alimentos utilizados no turismo, e cuidados com árvores frutíferas, como as figueiras, matéria-prima para a figada, doce típico da região. O doce de figo, seja ele em calda ou como figada, é uma prática sociocultural entre as mulheres das pousadas mais próximas. Na época do figo, elas colhem o fruto e se reúnem em uma das pousadas para a elaboração dos seus derivados. Depois os produtos são divididos igualitariamente, consumidos ou comercializados no turismo rural. 
Outro produto importante para o turismo e que é de domínio da mulher é o queijo serrano. Algumas propriedades ainda produzem o queijo, especialmente para o consumo na atividade turística, como prática cultural demonstrativa, e para a venda ao turista quando há excedente. A produção do queijo envolve toda a família. Os homens, na sua maioria, são os responsáveis por buscar as vacas no pasto e preparálas para a ordenha, realizada pelas mulheres. Enquanto isso, a mulher vai arrumando os equipamentos e os utensílios necessários para a ordenha. A ajuda do homem na ordenha é dada pelo número de animais. Depois da ordenha, os homens retornam com as vacas no pasto e organizam a estrebaria. Enquanto isso, as mulheres destinamse à casa do queijo (que em muitas propriedades já não existe mais) para preparar o produto. A produção é demorada e envolve, inicialmente, pelo menos uma hora de trabalho. Produzir queijo exige da mulher cuidados durante o dia todo e por dias consecutivos, visto que é necessário limpar e virar o queijo diariamente. Em uma das propriedades, é o homem que produz o queijo, porém, este fez cursos de qualificação para produzir melhor (tecnicamente, o que não quer dizer que o queijo que ele produza seja melhor) e outros tipos de queijo.

Esse fato remete ao trabalho de Nogueira (2004), quando a autora destaca três modalidades de turismo rural realizadas predominantemente pelos homens: o primeiro é um pesque-pague e restaurante caseiro, administrado somente pelos homens e cujas mulheres que trabalham são contratadas; o segundo é um sítio, que é considerado um dos principais produtos turísticos da região. Nele são desenvolvidas várias atividades, como produção de café, leite, reflorestamento, e há também ponto de venda de produtos coloniais, tudo administrado pelo homem. Nesse caso, as mulheres também são contratadas; a terceira é a propriedade do seu José, que, impossibilitado de trabalhar na agricultura por problemas de saúde, decidiu investir no turismo rural. Os exemplos trazidos ou são de empreendimentos de grande porte ou estão associados a uma atividade masculina, como a pescaria. Contudo, o que fica mais evidente a partir dos dados é a relação existente entre qualificação e atividade produtiva. No momento em que esta passa a ter caráter profissional, o homem busca a sua inserção e qualifica-se. Quando ela é uma produção doméstica e de autoconsumo, ela é da mulher, que realiza a mesma a partir dos conhecimentos adquiridos durante a sua vida. 
Ainda referente ao beneficiamento de produtos, são as mulheres, donas de casa, que são as responsáveis pela produção de doces (chimias e compotas), pães, bolachas, massas e licores, este último sendo dividido com os homens, pois, como é considerada bebida quente, sua identidade está relacionada ao masculino, assim como o carnear e fabricar produtos derivados da carne, como o salame ou a linguiça. $O$ beneficiamento destes produtos é realizado por elas mesmas, pois, conforme seus relatos, não confiam em outra pessoa para fazê-lo, fato identificado também nas pesquisas de Perez e Valiente (2000). Os achados de suas pesquisas identificaram a alimentação como sendo atividade que exige mais dedicação das mulheres, e é a única tarefa que não é delegada a outra pessoa. Já a limpeza da casa, dos quartos e da roupa são atividades que podem ser realizadas por outras pessoas sob a supervisão delas. Quando a elaboração destes produtos é feita fora da pousada, geralmente este trabalho é realizado por algum membro da família.

Além da alimentação, as mulheres são as responsáveis pela limpeza da casa, que compreende atividades de camareira, limpeza geral (varrer, lavar e encerar a casa). A limpeza da cozinha não é contabilizada aqui, pois se relaciona com o preparo dos alimentos. Fato importante desta atividade é o aumento do trabalho, considerado por todas as mulheres como um dos fatores de maior investimento do tempo, pois há necessidade de manter diariamente a casa limpa. Quando há hóspede, esse trabalho triplica, e isso justifica ser a atividade que mais emprega mulheres temporariamente nas pousadas e também a que mais recebe ajuda dos homens dentro da casa. Relacionada à limpeza da casa está o encerar e lustrar a casa. Todas as pousadas são construídas com a utilização de madeira, fato característico da região em função da existência de produção de madeira e também pelo clima. Encerar a casa é atividade da mulher, já o lustrar pode ser tanto delas quanto dos homens. Atrelado à limpeza da casa está a limpeza do pátio, cortar a grama, varrer, cuidar das flores. Com o turismo, essas atividades passaram a ter maior participação dos homens e a serem consideradas por elas como atividades secundárias. As atividades prioritárias relacionadas às mulheres são a alimentação e a limpeza da casa, que são consideradas as "peças-chave" para o desenvolvimento do turismo.

Além destas atividades, as mulheres realizam outras no turismo rural, como as relacionadas com a administração e a gerência da atividade. Mas o que compreende a administração do turismo rural? Compreende o planejamento 
das atividades a serem realizadas, as compras no mercado, as reservas dos hóspedes e a contabilidade. Como o turismo é uma atividade realizada dentro da casa, nesta circunstância da pesquisa, são as mulheres as mais envolvidas na administração das tarefas e isso está diretamente relacionado com o espaço em que estas atividades são realizadas, logo, a administração do turismo também será. Cabe destacar aqui que a administração está estritamente relacionada com a execução e não com o pensar da atividade. O pensar envolve todos os membros da família. Quando as atividades turísticas são realizadas no espaço externo à casa, como cavalgadas e passeios, estas ficam sob a responsabilidade do homem, já que são eles que as executam, conforme relata dona Fernanda:

[...] é que assim, o Marcio é mais da cavalgada, e de receber os turistas conversar, e essa parte de fazer comida e mandar na pousada é comigo, o que que eu vou fazer no dia dia é eu que decido, ele faz a cavalgada, aí é com ele, o resto é comigo, e a parte da execução também é com ele, assim conversar [...]. (Fernanda).

A fala retrata que não há um entendimento ainda do que compreende a atividade turística para essas famílias. Existe uma divisão de tarefas oriunda da divisão tradicional do trabalho. A pousada é minha, a cavalgada é dele, ou seja, as duas atividades não fazem parte de um mesmo produto, são tratadas por eles como separadas, como sempre foi dentro da estrutura de divisão sexual do trabalho. Isso faz pensar que a mulher não está mais inserida na administração da propriedade do que antes. Ela continua administrando o que é de seu domínio, a casa; e o homem continua administrando o que é de seu domínio, o campo. Essa constatação também foi evidenciada nos estudos de Rivera (2000), segundo a qual não se observou uma mudança no sistema atual de divisão sexual do trabalho, pois a mulher continua dentro do seu espaço físico habitual (a casa) e realiza as tarefas domésticas e reprodutivas, mesmo que a atividade turística tenha produzido efeitos significativos para as mulheres, como a valorização do seu trabalho; a maior independência econômica devido à sua contribuição ser mais visível; o aumento da qualidade de vida e da autoestima, obtida por meio do contato com outras realidades sociais e atividades, como as burocráticas e administrativas. Isto levaria a questionar sobre o papel do turismo nas relações de gênero: afinal, ele está mudando, ou até mesmo, transformando a posição da mulher dentro da propriedade ou apenas reforçando esta posição, agora na esfera pública? Os resultados trazidos 
aqui demonstram que há uma mudança na divisão de algumas tarefas, sobretudo das domésticas, mas que essa mudança pode ainda não ser suficiente para uma transformação no sistema de sexo/gênero.

Relacionada à administração está a contabilidade. A maioria das mulheres relata serem elas as responsáveis pela contabilidade, ou seja, receber os valores dos turistas e ter o controle das contas. Porém, quando questionadas se são elas que gastam esse recurso, a maioria respondeu negativamente. Elas ficam com o dinheiro e têm o domínio dele enquanto está dentro da casa. No momento em que esse recurso vai para o ambiente externo, elas já não têm mais controle sobre o mesmo. Elas, por vezes, participam das negociações, porém, não decidem, mesmo que esta envolva questões relacionadas a casa, como, por exemplo, as reformas, a aquisição de equipamentos e os utensílios domésticos, e também a compra de alimentos. A decisão, nesses casos, é sempre combinada. Essa combinação é feita no âmbito do casal quando não há filhos maiores, e quando há filhos, é uma combinação familiar.

A compra dos alimentos é um fator importante para se destacar, pois envolve a mobilidade espacial das mulheres rurais. Esta atividade é a que possui menor envolvimento da mulher, sobretudo quando diz respeito à efetivação da compra. São elas que fazem a "lista" das compras, o que precisa e a quantidade, porém não são elas que vão ao mercado buscar os produtos. Esse fenômeno está relacionado, especialmente, a dois fatores: a mobilidade das mulheres, aqui materializado no ter ou não Carteira Nacional de Habilitação (CNH), e ao tempo que esta atividade exige (pelo menos um turno), pois todas moram a pelo menos trinta quilômetros do centro da cidade e o acesso é por estrada de chão batido. As mulheres que possuem $\mathrm{CNH}$ planejam esse deslocamento para os dias em que não há hóspedes. As que não sabem conduzir veículos automotores necessitam do auxílio dos filhos ou do marido, sendo este um fator limitante, pois dependem do tempo deles. Para Perez e Valiente (2000), esta atividade é a que as mulheres menos dedicam tempo, e esse fato possui várias razões: grande parte dos produtos se tem em casa; outros são vendidos em feiras ambulantes; e, quando é necessário ir à cidade, são outros membros da família que o fazem. Outra atividade realizada pelas mulheres é o atendimento do hóspede ao telefone para efetivar a reserva. Essa tarefa ficou destinada a 
elas porque são elas que permanecem a maior parte do dia dentro de casa ou em seus arredores. A isto está relacionado também o trato pessoal, ou seja, a necessidade de ser simpática e atenciosa. As mulheres são, geralmente, mais atenciosas, conversam mais e são mais acolhedoras que os homens (PEREZ; VALIENTE, 2000; BRANDHT; HAUGEN, 2010a, 2010b).

Assim, esse exemplo de administração da atividade turística poderia muito bem desfazer convenções tradicionais de divisão sexual do trabalho com base no gênero. O trabalho de gestão da pousada com certeza é um grande salto na direção de mais poder e influência para as mulheres na propriedade. "No entanto, vemos que ela é concebida, ou recodificada, como qualquer trabalho doméstico ou trabalho de escritório e, assim, está sendo normatizada em termos de poder de gênero nas relações." (BRANDTH; HAUGEN, 2010b, p. 440).

Além da expressiva participação das mulheres no turismo rural, não se poderia deixar de mencionar a participação masculina, visto que esse estudo pretende compreender as relações de gênero no meio rural. Os homens são considerados pelas mulheres e por eles mesmos como "ajudantes" no turismo. A eles, com já dito, são destinadas tarefas realizadas no espaço externo a casa, como os passeios, as cavalgadas e a limpeza do pátio. Os passeios são atividades tidas como mais esporádicas do que a alimentação e a limpeza da casa, fato este que permite o envolvimento dos homens, já que eles não deixaram a atividade pecuária. Caso o homem não possa realizar estas tarefas, elas não são oferecidas aos turistas, o que raramente ocorre. A paisagem natural e o ambiente rústico são complementados por estas atividades e elas se fazem necessárias dentro do produto turístico, sendo dificilmente realizadas por terceiros, exceto em casos em que estes façam parte da família e do contexto da propriedade, pois exige conhecimento, envolvimento com a história e a cultura do local, além do conhecimento ambiental da propriedade e do seu entorno. Os passeios geralmente levam aos canyons e exigem organização e planejamento, principalmente nos aspectos tempo e espaço. Os homens também são os responsáveis pelas atividades de limpeza da parte externa da casa, como corte e capina do pátio e seus arredores, bem como auxiliam as mulheres em atividades como fazer o fogo, buscar lenha para o fogão e para a lareira, e tratar os pequenos animais. Assim como as mulheres, os homens têm 
importante presença nas decisões relacionadas com o turismo rural, em que tudo é combinado entre o casal, mas quem geralmente decide é o homem.

Mulheres e homens são fundamentais para o desenvolvimento do turismo nestas propriedades, em que cada um tem uma função a ser desempenhada. No entanto, cabe aqui destacar que a participação da mulher na execução das atividades turísticas é maior que a dos homens, visto que as atividades domésticas são a base para o desenvolvimento do turismo. Isso remete à coletânea de estudos organizados por Garcia Ramón e Ferré (2000), os quais destacam que o turismo rural é uma extensão do trabalho doméstico ou um trabalho doméstico ampliado, o que justificaria, também, o envolvimento "natural" da mulher com a atividade. Segundo Rivera (2000, p. 153),

Quando a unidade familiar identifica o trabalho no turismo como similiar ao doméstico (elaboração de alimentos, atenção a terceiras pessoas, limpeza da casa, etc.) se atribui imediatamente a mulher como a pessoa mais indicada para se encarregar do trabalho.

Contudo, há que se considerar que o turismo rural permite maior inserção das mulheres no mundo do trabalho produtivo e, consequentemente, maior valorização do trabalho feminino, ocasionando aumento da autoestima, melhoria da qualidade de vida, maior autonomia financeira, ampliação do ambiente de socialização, etc. "O elevado grau de satisfação que as mulheres apresentam com a inserção neste trabalho tem muito a ver com a possibilidade de manter a relação com diferentes pessoas, ver outros modo de vida, ter com quem falar, ter a mente mais aberta." (PÉREZ; VALIENTE, 2000, p. 190). Por outro lado, é possível identificar também a ampliação do trabalho doméstico feminino, como já relatado, o que poderia provocar um reforço a esse tipo de trabalho, ainda desvalorizado econômica e socialmente. Porém, cabe destacar que o turismo rural trouxe mudanças no comportamento do homem quanto à execução de atividades domésticas. Antes eles não ajudavam as mulheres em nenhuma atividade, hoje eles participam, mesmo que seja como ajuda, de boa parte das atividades domésticas. Brandth e Haugen (2010b) também identificaram essa mudança nas suas pesquisas. Para estes autores, os homens estão mais flexíveis e ajudando mais as mulheres nas atividades domésticas. Contudo, a "[...] necessidade de ambos, marido e mulher, intervirem para 
acomodar os convidados indica que o padrão de gênero comum nos casais rurais está desestabilizado e isso abre possibilidades para transgredir convencionais fronteiras de gênero" (BRANDTH; HAUGEN, 2010b, 435). Nesse sentido, o trabalho no turismo rural estaria mudando o comportamento de alguns membros e reforçando o de outros. Porém cabe pensar até que ponto essas mudanças são significativas para uma transformação no sistema de sexo/ gênero. Visto por outro lado, é possível dizer que o turismo rural é uma semente que foi plantada visando estas mudanças, mas que ainda é necessário tempo para ela germinar e crescer.

Nesse sentido, o que se apresentou são as diferentes atividades realizadas por homens e mulheres e o envolvimento de cada membro da família na atividade turística. Cabe destacar que o trabalho da mulher apresenta-se como indispensável para o turismo, visto que as atividades por elas desempenhadas para a família e para o turista são as mesmas. O turismo, nas famílias aqui pesquisadas, proporcionou aumento de trabalho para os membros da família, o que resultou na necessidade de contratar mão de obra externa, seja para o trabalho realizado no turismo ou na pecuária.

No que diz respeito ao trabalho contratado no turismo rural, este está estruturado com base em "ciclos" de trabalhos, que têm intensidade nos períodos de férias e feriados prolongados. Neste período a frequência de contratação de mão de obra é maior do que nos demais, sendo essencialmente de mulheres com vínculos de parentesco, como primas, cunhadas, sobrinhas, ou, ainda, vizinhas. Essas mulheres são contratadas como diaristas, ou seja, pessoas que trabalham por dia. Aquelas que não são casadas e não têm filhos permanecem na propriedade por período mais longo, fato que permite que a mão de obra feminina jovem seja contratada. Isso ocorre porque as propriedades são distantes da cidade e também de outras propriedades, dificultando a mobilidade das pessoas contratadas. A cidade não oferece trabalho para todos seus habitantes, a não ser na época de colheita da maçã e da batata, período em que muitas mulheres se envolvem no trabalho de colheita com seus maridos ou pais, gerando uma receita extra para a família.

As mulheres no turismo são contratadas para realizar tarefas relacionadas 
com a limpeza da casa, como passar cera, limpar os banheiros e vidros, atividades que são consideradas mais demoradas e "pesadas". Além disso, cabe a elas o desempenho de funções de camareira e de auxiliar de cozinha. Como auxiliares de cozinha, elas preparam as saladas, lavam e cortam legumes e lavam a louça. Estas atividades representam o caráter doméstico da contratação do serviço no turismo, sem qualificação, esporádico e informal, sendo que as mulheres apenas reapresentam o trabalho realizado por elas nas suas casas, que foi aprendido e passado de mãe para filha sem qualquer qualificação profissional. Porém, esse trabalho tem que ser caprichado, porque quem vai usufruir dele não é a proprietária da pousada, mas sim os turistas, que devem deixar a pousada satisfeitos com o serviço adquirido, e esta satisfação está relacionada, sobretudo, com a qualidade dos serviços apresentados, incluindo nele a limpeza e a organização da casa.

O trabalho contratado temporariamente é esporádico e considerado como auxiliar e hierarquizado. Um exemplo disso é a alimentação. A alimentação é um dos principais produtos das propriedades turísticas, representando a valorização social e cultural da pousada. Assim, esse alimento deve ser preparado pelas donas da casa e não pelas mulheres contratadas, evidenciando o caráter de hierarquia entre as mulheres trabalhadoras, relacionado, sobretudo, à valorização desta atividade.

A limpeza da casa também é tida como de extrema importância para a qualidade dos serviços prestados, sendo esta também dividida e hierarquizada. A limpeza dos quartos, por exemplo, mesmo que tenha significativa participação das mulheres contratadas, está sob a gerência das donas da casa e aquelas somente são solicitadas quando estas não conseguem desenvolver o trabalho sozinhas, fato também identificado por Perez e Valiente (2000), que identificaram que a limpeza da casa, dos quartos e da roupa são atividades delegadas a outras pessoas, sob a supervisão das proprietárias. Mais uma vez, a contratação assume o caráter de ajuda, ou seja, mesmo as mulheres que sempre foram consideradas como ajudantes na agricultura, continuam ocupando a mesma "categoria" quando são contratadas no turismo, permanecendo ainda a divisão tradicional de gênero. Porém, esse tipo de trabalho é dado a uma pessoa de confiança da mulher empreendedora, fato que justifica a contratação de 
mulheres com vínculo de parentesco e de proximidade, como as vizinhas. Outro fato importante a destacar é a falta de mão de obra no mercado para esse tipo de serviço. Ensinar uma pessoa conhecida ou da família se torna mais fácil e acessível para elas e isso é justificado pela aproximação na criação, quando se trata da família. Geralmente elas foram criadas no mesmo ambiente social, o que facilita muito, como relata dona Janete: [...] é o mesmo jeito da gente, fica mais fácil [..]. Assim, o trabalho no turismo rural é uma reapresentação do trabalho realizado em suas casas, um trabalho doméstico contratado, que tem caráter auxiliar. Elas estão ali para auxiliar as donas das pousadas e não para substituí-las, como pode ser confirmado por meio do depoimento da dona Janete: [...] tem... um contrato temporário... qui daí eu tenho duas primas qui mi ajudam... qui me auxilia né [...]. Esse depoimento enfatiza seu posicionamento em relação ao trabalho contratado das primas: é auxiliar.

Além do caráter doméstico do trabalho realizado pelas mulheres no turismo rural, esse trabalho não traz nenhum benefício previdenciário, férias, $13^{\circ}$ salário, auxílio maternidade, etc., para as mulheres contratadas. O caráter de "diarista" não exige contrato formal de prestação de serviços, eximindo, assim, qualquer tipo de encargo e/ou benefício, seja ele previdenciário ou de outro tipo para as mulheres. Muitas delas, especialmente asjovens, não possuem bloco de produtora rural, situação que as exclui, assim, também de seus direitos como agricultoras. Para as mulheres jovens, isso é mais agravante. Quando questionadas se gostam de trabalhar no turismo rural, todas afirmaram que sim, que é um trabalho bom de realizar, além de não exigir qualificação e gerar recurso financeiro para elas e para a família. As mulheres estão aproveitando seus conhecimentos adquiridos pelo trabalho doméstico desde a sua infância em uma atividade profissional, que está inserindo-as no mercado de trabalho rural, porém, no mercado de trabalho informal e arraigado na divisão sexual tradicional, ou seja, o que está ocorrendo é uma repaginação do trabalho das mulheres.

Contudo, em nenhum momento foi manifestada a vontade delas de continuar na mesma atividade e se qualificarem, tornando-se assim profissionais da área. Esse fenômeno, constatado também por Nogueira (2004) com as mulheres que trabalham no agroturismo, pode estar, segundo a autora, relacionado à falta de afirmação das práticas do agroturismo como ocupação profissional, 
ISSN: 1983-7151

que resulta do agroturismo ser uma atividade profissional ainda nova na região e a dificuldade de reconhecer as atividades do agroturismo como um tipo de trabalho, por este ser subsidiário e complementar em relação a outras atividades. O primeiro fenômeno é também identificado nos Campos de Cima da Serra. Já no segundo, as percepções diferem. Na região aqui estudada o turismo rural passou de atividade complementar e subsidiária para atividade principal economicamente, sendo que na maioria das famílias ele passa a dar sustentação econômica para a pecuária, o que não acontece na região estudada por Nogueira (2004). É possível também identificar o turismo rural como uma atividade relacionada à mulher rural, pela sua proximidade com as atividades domésticas, o que não exclui os homens do seu desenvolvimento.

Os homens também são mão de obra contratada pelo turismo, contudo, em menor número e para atividades que possam ser aproveitadas tanto para o turismo como para a pecuária, otimizando assim o trabalho. Apenas uma propriedade contrata um homem com periodicidade maior, com um número estipulado de dias por semana. Mesmo assim, esse não possui vínculo empregatício com a propriedade. As tarefas realizadas por estes "diaristas" são: limpeza do pátio, preparação da terra para lavoura, e de canteiros para a horta, no recolhimento de esterco, de aparamento da grama e realização de algum tipo de reparo em equipamentos ou na estrutura física da propriedade. Estas atividades são também consideradas como auxiliares e são gerenciadas por algum membro da família, geralmente homem: [...] é, ele ajuda, ele não trabalha diretamente fixo [...] (João). O depoimento do entrevistado evidencia, novamente, o caráter valorativo do trabalho. O trabalho é de ajuda, por isso ele não é fixo. No momento em que este trabalho for considerado indispensável, talvez esse caráter também mude. 0 mesmo fato acontece em relação ao trabalho das mulheres contratadas.

Além do trabalho de diaristas, outro tipo de trabalho que é utilizado pelas pousadas, tanto para atender a demanda no turismo como na pecuária, é a contratação de trabalho terceirizado. O trabalho terceirizado se dá de duas formas: uma é pelo beneficiamento de produtos utilizados no turismo, como pães, bolachas, queijo, embutidos e doces. Esse trabalho é realizado pelas mulheres. O outro tipo é a contratação de horas-máquina ${ }^{6}$. Estas horas são

6 Hora-máquina é o tipo de serviço contratado utilizando máquinas agrícolas. 
destinadas principalmente para o preparo da terra na plantação de pastagens ou de alguma cultura agrícola. O fato de desprender o recurso "máquina" remete este trabalho aos afazeres masculinos, pois são eles os detentores desse equipamento e dos saberes relacionados a ele.

Vale destacar que as famílias pluriativas possibilitam a inserção das mulheres no mercado de trabalho rural local, mesmo que informal, sendo este fato não identificado nas famílias agrícolas. Isto está relacionado ao aumento do trabalho da mulher, sobretudo das tarefas domésticas. No entanto, esse dado traz para a discussão se esta inserção está se dando da forma adequada para estas mulheres, ou se não estaria reforçando ainda mais o trabalho doméstico e sem valor produtivo da mulher rural. É reconhecido que, se estas mulheres não estivessem trabalhando no turismo, ou estariam "sem ocupação produtiva", ou estariam ocupadas em atividades agrícolas sazonais, como, por exemplo, a colheita da maçã e da batata ou apenas com o trabalho doméstico. Assim, como outros trabalhos agrícolas, o trabalho no turismo rural continua sendo desqualificado e informal, sendo este caracterizado como trabalho de "diarista". No entanto, há que se destacar que o turismo rural insere as mulheres no mercado de trabalho, sobretudo as contratadas, e pouco os homens. O trabalho de homens é menos valorizado nesta atividade que o das mulheres, e quando necessário, os próprios homens das propriedades o desenvolvem, salvo naquelas propriedades onde o homem está à frente da atividade turística ou quando a produção pecuária exige muito envolvimento. A contratação masculina se dá para as funções agrícolas, já que estas sim são "coisa de homem", como se verá no item a seguir.

\section{OS "SIGNIFICADOS" DO TRABALHO NO TURISMO RURAL}

O propósito deste item é se tratar dos significados que assume o trabalho no turismo para homens e mulheres rurais. Estuda-se uma realidade específica de turismo rural e é com base nisso que se procurou traçar algumas considerações sobre o que representa essa nova atividade para homens e mulheres que nela estão envolvidos. A palavra que traduz os significados do trabalho no turismo é "valorização". Esta valorização se dá por meio dos seguintes aspectos: valor 
econômico, valor social, valor do trabalho, seja ele doméstico ou agrícola. Tentarse-á refletir sobre estas diferentes formas de valorização no entendimento de homens e mulheres.

Em primeiro lugar, o trabalho no turismo representa, tanto para homens como para mulheres, valor econômico e é por isso que eles decidiram investir na atividade, fato também identificado nas pesquisas de Nogueira (2004) e Garcia Ramón, Cànoves e Valdovinos (1995). A receita auferida por esta atividade representa, hoje, para a maioria das famílias, a principal fonte de recursos financeiros. Os ganhos oriundos do turismo rural ultrapassam os ganhos obtidos pela produção do queijo, segunda atividade econômica de maior importância antes do turismo rural e da pecuária, tornando-se em muitas das famílias pesquisadas a fonte de receita que possibilita a manutenção da pecuária. Para as mulheres, o turismo representa mais que fonte de receita, representa a valorização do seu trabalho doméstico, mesmo que este tenha aumentado. Antes do turismo, o trabalho realizado por elas não tinha valor econômico para a família, era invisível. Hoje, essa valorização mudou devido, sobretudo, à sua importância econômica e social para a família.

Para Rivera (2000), quando o turismo passa a ser uma atividade econômica significativa para a propriedade, ele deixa de ser tratado como uma extensão do trabalho doméstico e passa a ser considerado como profissão que tem na participação masculina um aumento significativo. Como a mulher, que antes não era considerada como provedora de receita, agora tem sob seu controle uma das principais atividades e de fonte de receita da propriedade? Para elas, essa receita não é obtida apenas pelo seu trabalho, e sim pelo trabalho da família, mesmo que o seu seja indispensável. Definir quem é ou quem são os responsáveis por esta atividade não é a sua maior preocupação. O importante para elas é que, com o turismo, a receita da família aumentou e, consequentemente, a qualidade de vida também. Para as mulheres, o turismo representa um conjunto de atividades, sincronizadas, que precisam tanto do homem quanto da mulher. Se o homem não estivesse presente, atividades como os passeios e as cavalgadas não seriam possíveis, e estas são atividades consideradas muito importantes por todos, já que elas estão relacionadas com a natureza, com o clima e com os cânions, componente fundamental do produto turístico na região. 
Para o homem, essa valorização do trabalho não é a mesma. O homem sempre teve seu trabalho valorizado dentro da propriedade, pois sempre foi ele o responsável por manter economicamente a propriedade por meio da atividade agrícola. Com o turismo, o seu trabalho passou por mudanças significativas, contudo, estas estão relacionadas ao tipo de tarefa desempenhada. Tarefas que antes não eram realizadas por ele, como ajuda nas atividades domésticas, passam, agora a ser realizadas. Antes, a prioridade era a pecuária e a dedicação era total a esta atividade. Hoje, a prioridade é o turismo rural, passando as atividades relacionadas com a pecuária por rearranjos. Contudo, mesmo com essa mudança, o fato de precisarem se dedicar a duas atividades não influenciou na valorização do seu trabalho, nem para menos, com o envolvimento nas tarefas domésticas; e nem para mais.

Outro fato evidenciado nos depoimentos dos entrevistados é sobre a valorização do trabalho das mulheres pelos homens. Com o turismo rural, o trabalho da mulher teve significativo aumento, ocasionando uma visibilidade maior de suas tarefas. Essa evidência fez com que os homens valorizassem mais a função exercida por ela dentro da propriedade, fato que em nenhum momento esteve relacionado com o recurso financeiro, ou seja, os homens não valorizam mais o trabalho das mulheres porque está gerando receita para a família, e sim pela visibilidade que o trabalho feminino teve com o turismo e a sua importância para o funcionamento da atividade. Tanto homens quanto mulheres deixam claro em seus relatos que o turismo rural só está trazendo benefícios, porque toda a família está envolvida, não é uma atividade de homens ou de mulheres, mas sim da família, com uma proporção de dedicação diferenciada para homens e mulheres. Contudo, não se pode afirmar veementemente que o turismo é uma atividade mais ou menos feminina ou masculina e caracterizá-la como tal. O que se pode evidenciar empiricamente é que existe uma proximidade maior da mulher com a atividade, por esta ser realizada dentro de casa e por ser uma extensão do seu trabalho doméstico. Para Perez e Valiente (2000), " [...] alta valorização do trabalho no turismo se deve também a que é uma forma de demonstrar aos demais e a si mesmas que sabem fazer outra coisa que não seja ir para a horta, ocupação exclusiva da mulher, no espaço doméstico e, portanto sem valor social" (p. 191). Essa mudança, porém, não é relatada pelos homens. Os homens, sim, passaram 
ISSN: 1983-7151

a valorizar mais o trabalho da mulher, devido ao seu envolvimento em atividades que até então eram desempenhadas apenas por elas.

Além do valor econômico, o turismo traz implícitos valores sociais e culturais, que significam mudanças positivas e negativas. Nesse sentido, há uma forte valorização social destacada pelas mulheres a partir do convívio com os turistas. Hoje, o turismo é visto, especialmente pelas mulheres, não só como uma fonte de recurso econômico para a família, mas também como uma fonte de conhecimento cultural, de redução do isolamento e de envolvimento social (socialização). Contudo, essa visão não é destacada pelos homens. Para eles, o turismo rural proporcionou isso as mulheres. Isso também se constata nos resultados dos trabalhos de Rivera (2000), Garcia Ramón e Ferré (2000), os quais destacam a sociabilidade das mulheres como uma das principais mudanças ocorridas com o desenvolvimento do turismo rural. Perez e Valiente (2000) também identificaram mudanças nas regiões estudadas. Para elas, o turismo rural representa para as mulheres da Galícia uma possibilidade de manter relações com outras pessoas, ver outros modos de vida, ter com quem conversar, ter a mente mais aberta, integrar-se ao mundo exterior.

Em síntese, as informações até aqui apresentadas demonstraram que houve mudanças nas estruturas das relações de trabalho de homens e mulheres a partir do turismo rural, as quais culminaram na reorganização das atividades produtivase reprodutivas das famílias pesquisadas. No entanto, estas pequenas mudanças não foram capazes de transformar a divisão sexual do trabalho tradicional e a posição subsidiária do trabalho da mulher, visto que o turismo rural é uma atividade que tem como base o trabalho doméstico, considerado como complementar e inferior hierarquicamente. As mudanças que ocorreram devem-se ao fato de agora as atividades domésticas serem pagas e públicas e representarem parte da receita das famílias, gerando, assim, uma nova configuração simbólica sobre suas vidas e as relações sociais e familiares. Contudo, essas mudanças não foram capazes de transformar a hierarquia e o status do trabalho de homens e, especialmente, das mulheres nestas famílias. Para Nogueira (2004), o agroturismo apresenta-se como um lócus em que se reproduzem as relações de gênero presentes em toda a sociedade, ou seja, está-se diante de uma permanência dentro da mudança, parafraseando Bourdieu (2002). 
Para Perez e Valiente (2000), pouco pode se esperar do turismo rural como um motivador de mudança nas relações de gênero, visto que o turismo é uma atividade nova, que está se mantendo com base no trabalho da mulher rural, e que tem nele a extensão do trabalho doméstico. Efetivamente, a estacionalidade desta ocupação, a simultaneidade com o trabalho reprodutivo, a utilização do espaço doméstico e o fato de não precisar de uma formação específica são elementos que impedem que esta atividade seja valorizada, sendo esta considerada como "baixo-emprego", portanto, pouco útil como fator de mudança. Corroborando as autoras e os resultados de nossa pesquisa, Nogueira (2004) também aponta para uma divisão sexual do trabalho e desigual valoração do trabalho realizado por homens e mulheres. A autora demonstra em seu estudo que o agroturismo reproduz, de forma (re)significada, uma tradicional divisão sexual do trabalho, em que homens são os responsáveis pelas atividades agrícolas; e mulheres, pelas tarefas domésticas. Atrelado a isto está a dificuldade de contabilizar o trabalho da mulher rural, tanto o doméstico quanto o produtivo e, também, agora o do turismo. Para Garcia Ramón (1990), o trabalho da mulher na produção é difícil de classificar e valorar, pois é descontínuo, fracionado e irregular, porque ela está disponível ao que convém para a unidade familiar, tanto na produção como na reprodução e, geralmente, é um trabalho de apoio.

O trabalho realizado no turismo rural aparece subordinado às responsabilidades familiares da mulher, pois esse somente é realizado porque houve o entendimento da família de que era possível desenvolvê-lo sem prejudicar os cuidados dela com a família. Esse fato pode ser a justificativa para, na grande maioria das pousadas, não possuírem filhos pequenos, que exigem mais cuidados. Mas talvez seja essa a grande descoberta, que o turismo rural pode ser conciliado com as responsabilidades domésticas e ainda gerar emprego e rendimento para as mulheres rurais, mesmo estando atrelado às atividades domésticas, pois ele permite que estas mulheres invistam como gestoras e administradoras, como empreendedoras, mesmo que a mulher esteja "inserida na unidade familiar e fortemente condicionada por tal inserção e não isolada ou como sujeito individual" (BONI, 2005, p. 58). 
O objetivo central deste estudo foi compreender a organização do trabalho em empreendimentos de turismo rural. Para isso, buscam-se fundamentos nos conceitos de separação e hierarquização. Separação no sentido de que há trabalhos de homens e de mulheres, e hierarquização no sentido da valorização destes trabalhos. Esta divisão ficou evidente a partir da análise dos nossos dados, em que, mesmo com o turismo, as práticas masculinas e femininas continuam praticamente inalteradas.

A separação das atividades realizadas no turismo, na atividade agrícola e no ambiente doméstico não difere da compreensão da divisão sexual do trabalho tradicional, baseada no sistema de gênero. Atividades de caráter masculino continuam sendo de responsabilidade de homens, enquanto atividades de caráter feminino continuam predominantemente sendo de responsabilidade das mulheres. As mulheres são as responsáveis pelas atividades que estão relacionadas à manutenção reprodutiva da família, ou seja, as de caráter doméstico, como os cuidados da casa e da família. A execução destas atividades muda pouco com a inserção do turismo. O que ocorre é que há reformulações nas configurações deste trabalho, como o aumento de horas trabalhadas, de tarefas e de responsabilidades, pois, agora, além dos cuidados com a família, a mulher precisa dedicar-se a outra atividade. Os homens, mesmo no turismo, são os responsáveis por atividades identificadas como sendo masculinas. A eles coube a organização externa da casa, como a limpeza do pátio, o trato dos animais, especialmente os cavalos utilizados nas cavalgadas, o acompanhamento das trilhas ecológicas, etc. O fato novo que ocorre é que os homens passam a se inserir mais nas atividades tidas como domésticas, e essa é a mudança sentida na organização do trabalho, pois isso sempre foi visto como uma das barreiras na divisão sexual do trabalho a ser transposta. Atrelada à separação está a hierarquização das atividades caracterizadas como "ajuda" e complementar. O que se pode destacar aqui é que, mesmo no caráter "ajuda e complementar", as tarefas são hierarquizadas, levando em consideração os critérios apontados pelo sistema de divisão sexual do trabalho tradicional. 
Assim, pode-se concluir que o turismo rural provocou uma ressignificação e reprodução da forma tradicional da divisão sexual do trabalho nas famílias rurais pesquisadas, sobretudo no que diz respeito ao trabalho feminino. O que ocorre agora é uma reorganização simultânea do trabalho no campo assalariado e no campo doméstico depois do desenvolvimento do turismo, afetando tanto homens quanto mulheres, em virtude de que surge uma nova divisão do trabalho familiar, seja ele doméstico ou agrícola, mesmo que ainda permaneçam as estruturas da forma tradicional da divisão sexual do trabalho. Contudo, há que se destacar que houve avanços e que se deve levar isso em consideração.

\section{REFERÊNCIAS}

BONI, Valdete. Produtivo ou Reprodutivo: O trabalho das mulheres nas agroindústrias familiares - um estudo na região oeste de Santa Catarina. 2005. 99f. Dissertação (Mestrado em Sociologia Política) - Centro de Filosofia e Ciências Humanas, Universidade Federal de Santa Catarina, Florianópolis, 2005.

BOURDIEU, Pierre. A dominação masculina. Rio de Janeiro: Bertrand Brasil, 2002.

BRANDTH, Berit; HAUGEN, Marit S. Gendered Work in Family Farm Tourism. Journal of Comparative Family Studies, Calgary, v. 35, n. 2, p. 379-393, 2010a.

Doing Farm Tourism: The Intertwining Practices of Gender and Work. Journal of Women in Culture and Society, Chicago, v. 35, n. 2, p. 425-446, $2010 \mathrm{~b}$.

CARNEIRO, Maria José . Ruralidade: novas identidades em construção. Estudos Sociedade e Agricultura, Rio de Janeiro, n.11, p. 53-75, out. 1998.

GARCIA RAMÓN, Maria Dolors. La division sexual del trabajo y el enfoque del género en el estudio de la agricultura de los paises desarrollados. Agricultura y Sociedad, Madrid, n. 55, p. 251-277, abr./jun. 1990.

GARCIA RAMÓN, Maria Dolors; CANOVES, Gemma; VALDOVINOS, Nuria. Farm tourism, gender and the environment in Spain. Annals of Tourism Research, New York, v. 22, n.2, p. 267-282, 1995.

GARCIA RAMÓN, Maria Dolors; FERRÉ, Mireia Baylina. El nuevo papel de las mujeres en el desarrollo rural. Barcelona: Oikos-tau, 2000. 
HIRATA, Helena; KERGOAT, Daniele. Novas configurações da divisão sexual do trabalho. Cadernos de Pesquisa, v. 37, n. 132, p. 595-609, set./dez. 2007.

MORELL, Ildikó Asztalos; BOCK, Bettina B. Rural gender regimes: the development of rural gender research and desing of a comparative Approach. In: MORELL, Ildikó Asztalos; BOCK, Bettina B. Gender regimes, citizen participation and rural restructuring. Elsevier, 2008. P. 03-32.

MORELL, Ildikó Asztalos; BRANDTH, Bent. Gendered Work in Family Farm Tourism. Journal of Comparative Family Studies, v. 38, n. 3, p. 371-377. 2007.

NOGUEIRA, Verena Sevá. A “Venda Nova das Imigrantes": relações de gênero e práticas sociais no agroturismo. 2004. 258. Dissertação (mestrado em sociologia) - Instituto de Filosofia e Ciências Humanas, Universidade Estadual de Campinas, Campinas, 2004.

PÉREZ, Montserrat Villarino; VALIENTE, Gemma Cànoves. Turismo rural em Galicia: sin mujeres imposible. In: GARCIA RAMÓN, Maria Dolors; FERRÉ, Mireia Baylina. El nuevo papel de las mujeres em el desarrollo rural. Barcelona: Oikos-tau, 2000. p. 171-198.

RIVERA, Alba Caballé. Implicaciones de gênero em el desarrollo de la oferta de agroturismo em Navarra y Astúrias. In: GARCIA RAMÓN, Maria Dolors; BAYLINA, Ferré Mireia. El nuevo papel de las mujeres em el desarrollo rural. Barcelona: Oikos-tau, 2000. P. 153-169.

SCHNEIDER, Sergio. A pluriatividade como estratégia de reprodução social da agricultura familiar no Sul do Brasil. Estudos Sociedade e Agricultura, Rio de Janeiro,v. 16, p. 164-184, 2001.

UNIVERSIDADE FEDERAL DO RIO GRANDE DO SUL - UFRGS. Faculdade de Biblioteconomia e Comunicação. Núcleo de Fotografia. Povo e Paisagem de São Jose dos Ausentes. Disponível em: <www.ufrgs/fotografia.br>. Acesso em: 23 abr. 2011. 